\title{
Dimensionamento do Sistema de Recalque para abastecimento de água da comunidade de Macundú, distrito de São João Marcos, município de Rio Claro, Rio de Janeiro.
}

\section{Sizing the pumping system for the water supply in Macundú comunity, São João Marcos district, Rio Claro, Rio de Janeiro.}

Artigo

Original

\author{
Damião Justino ${ }^{1}$ \\ Élcio Nogueira ${ }^{2}$
}

Original

Paper

\section{Palavras-chave: \\ Ligas de Titânio \\ Envelhecimento}

Dureza

Biomateriais

\section{Resumo:}

Este trabalho visa à elaboração de um roteiro prático, para dimensionar sistemas elevatórios de água, baseado em estudos demográficos, topográficos, fórmulas matemáticas e dados experimentais de laboratório e, principalmente, visa propor a implantação de um sistema de abastecimento de água na comunidade do Macundú. O sistema existente nessa comunidade foi criado sem técnica e muito menos material adequado e, com o crescimento do povoado e sucessivas ampliações mal elaboradas, tal sistema se mostra incapaz de atender a demanda dos moradores. A seleção de uma bomba é feita em função da vazão e da altura manométrica da instalação. A vazão depende do consumo diário da instalação, jornada de trabalho da bomba e do número de bombas em funcionamento. A altura manométrica é determinada em função do levantamento topográfico do perfil do terreno mais a perda de carga nas tubulações. Feito isso, as possíveis bombas são selecionadas através de mosaicos, diagramas ou tabelas de seleção de bombas. Posteriormente, deve-se fazer análise das curvas características dessas bombas para determinar qual atenderá de melhor maneira aos parâmetros: potência requerida, rendimento e NPSH. Para este projeto, foi possível selecionar uma bomba que possa trabalhar com eficiência, mas o processo de determinação de moto-bomba para um sistema de recalque é bem mais complexo do que parece, não bastam ter em mãos um mosaico, diagrama ou tabela de seleção de bombas, todos os parâmetros inerentes devem ser levados em consideração para definir a opção mais viável. Se isso não for obtido, todo o sistema deve ser redimensionado.

\section{Abstract}

The work aims to develop a practical roadmap to scale pumping systems for water based on demographics, topography, mathematical formulas and of experimental data. Propose the creation of a system of water supply in Macundú community, in Rio Claro city, state of Rio de Janeiro . The existing system was created improperly. With the growth of the community, the current system is unable to meet the demand of residents. In this work, the selection of pumps is designed in relation to flow and dissipation of energy along the hydraulic system. The flow rate depends on the daily consumption of the installation, work load of the pump and number of pumps in operation. The system is determined by the profile of the terrain, with the aid of appropriate equipment. Thereafter, the pumps are selected through mosaics, diagrams or tables. Subsequent analysis should be made through the characteristic curves of pumps to determine what of them best meets the design parameters: efficiency, power, and NPSH. For this project it was possible to select a pump that can operate efficiently, but the process of determination of motor-pump to this kind of system is much more complex than it seems. It is not enough to have on hand a diagram, or mosaic for selection of pumps. All parameters involved should be considered for defining the most viable option. If the designed system fails, the completely system should be resized and reconsidered.
Key words:

Titanium alloys

Aging

Hardness

Biomaterials
Recebido em $12 / 2011$

Aprovado em 03/2012

\footnotetext{
${ }^{1}$ Acadêmico do curso de Engenharia Civil do Centro Universitário de Volta Redonda - UniFOA

${ }^{2}$ Professor Doutor - Engenharia Mecânica - UniFOA
} 


\section{Introdução}

A água é o constituinte inorgânico mais abundante na matéria viva, no homem, mais de $60 \%$ do seu peso é constituído por água, seu papel no desenvolvimento da civilização é reconhecido desde a mais alta antiguidade; Hipócrates (460-354 A.C.) já afirmava: "a influência da água sobre a saúde é grande”. O homem tem necessidade de água de qualidade adequada e em quantidade suficiente para todas suas necessidades, não só para proteção de sua saúde, como também para o seu desenvolvimento econômico. Assim, a importância do abastecimento de água deve ser encarada sob o aspecto sanitário e econômico. Assinale-se que a qualidade e a quantidade de água a ser utilizada num sistema de abastecimento estão intimamente relacionadas às características do manancial. CARESTIATO, A. \& ABREU (1999).

Segundo Porto (2004), a localização de muitas cidades em cotas bastante elevadas em relação aos recursos próximos, ou à enorme distância dos recursos que se encontram em posição mais alta que a cidade, constitui obstáculos à adoção de sistemas que funcionam por gravidade, no qual há o aproveitamento da energia potencial de posição para o transporte da água. Devido a tal fato, se faz necessário transferir energia para o líquido, por meio de um sistema eletromecânico, a fim de vencer esses obstáculos. Um conjunto destinado a elevar água denomina-se sistema elevatório ou sistema de recalque.

\section{Objetivos}

O presente trabalho visa propor a implantação de um sistema de abastecimento de água na comunidade Macundú, almejando progresso e melhoria para as condições de vida dos habitantes. O sistema existente foi criado pelos antigos fazendeiros, sem técnica e muito menos material adequado e com o crescimento do povoado e sucessivas ampliações mal elaboradas, tal sistema se mostra incapaz de atender as necessidades dos moradores. Esse sistema de abastecimento deve ser completo, com: capitação, elevatória, estação de tratamento de água (ETA) e rede de distribuição. Contudo, o foco de abordagem deste trabalho é a elevatória ou sistema de recalque. Além disso, visa à elaboração de um roteiro prático e eficiente para dimensionamento de um sistema de recalque, incluindo: captação, elevatória (conjunto moto-bomba) e adutora de água bruta, baseado em dados demográficos e topográficos, fórmulas matemáticas e dados experimentais de labor

\section{Metodologia}

Para dimensionar um sistema elevatório, deve-se, inicialmente, fazer um estudo de campo a fim de obter todos os dados necessários. Tal estudo deve conter: levantamento do perfil topográfico da localidade, da captação a estação de tratamento de água, incluindo um esboço com os comprimentos das tubulações de sucção e recalque e todas as respectivas conexões e cotas de nível; definição do manancial (rio, lago, poço, etc.) bem como a sua capacidade de vazão, qualidade da água e ponto de captação; levantamento populacional dos últimos vinte anos, incluindo número de residências por classe social, prédios residenciais, públicos, comerciais, industriais, mapa urbanístico da localidade (Figura 01), etc.

\section{Ver Figura 01}

Posteriormente, deve-se determinar: a vazão (Q) a ser recalcada; o diâmetro da tubulação de recalque e de sucção (Dr e Ds respectivamente); a altura manométrica (Hman); a potência (Pot); o rendimento $(\eta)$ e o NPSH disponível. Com esses dados e utilizando o catálogo de uma bomba comercial, pode-se selecionar as possíveis bombas. Somente então deve ser solicitado, dos fabricantes, as curvas características das bombas selecionadas para então definir a opção mais viável. 


\section{Desenvolvimento}

\section{a. Determinação da vazão de serviço}

Segundo informações de profissional da CEDAE (companhia estadual de água e esgoto do Rio de Janeiro) a elaboração de um projeto de abastecimento de água exige o conhecimento das vazões das diversas partes constitutivas do sistema. Os problemas de dimensionamento das canalizações, estruturas e equipamentos, implicam estudos diversos que incluam a verificação do consumo médio por pessoa, a estimativa do número de habitantes a ser beneficiado e as variações de demanda que ocorrem por motivos vários.

A água conduzida para uma cidade enquadra-se numa das seguintes classes de consumo ou de destino: doméstico; comercial ou industrial; público; perdas e fugas. As vazões destinadas ao uso doméstico variam com o nível de vida da população, sendo tanto maiores, quanto mais elevado esse padrão. Com relação à água para uso comercial, destaca-se a parcela utilizada pelos restaurantes, bares, hotéis, pensões, postos de gasolina e garagens, em que se manifesta um consumo muito superior ao das residências. Quanto às indústrias, aquelas que utilizam a água como matéria-prima ou para lavagens e refrigeração, estas apresentam consumos mais elevados. Na água para uso público inclui-se a parcela utilizada na irrigação de jardins, lavagem de ruas e passeios, edifícios e sanitários de uso público, alimentação de fontes, esguichos e tanques fluxíveis de redes de esgoto (CARESTIATO, A. \& ABREU -1999).

A norma do Extinto Departamento de Obras Sanitárias do Estado de São Paulo, aplicável a projetos de cidades do interior, o valor indicado de duzentos litros de água por habitante por dia (200 L/hab./dia), portanto, como o dimensionamento da vazão de água é feito com base em um número de habitantes, para se determinar a vazão requerida por uma comunidade, se faz necessário determinar, primeiramente, o número de habitantes a ser atendido e, a previsão de crescimento populacional após vinte anos, no mínimo. Tal previsão não é fácil de ser determinada, visto que o crescimento populacional varia muito de região para região, no entanto, estudos estatísticos mostraram que a comunidade do Macundú se mantém estagnada nos últimos dez anos. Fato que se deve à característica acidentada do relevo, à localização geográfica distante dos grandes centros urbanos e às péssimas condições de acesso (estrada de terra batida), o que dificulta a produção agropecuária e praticamente impossibilitando a atividade industrial. Com isso, podemos concluir que a comunidade do Macundú permanecerá com a sua população praticamente inalterada pelos próximos vinte anos.

Segundo dados fornecidos pela secretaria de saúde da prefeitura de Rio Claro (PAULA, D.A. - 2004), a comunidade do Macundú se encontra atualmente com 357 residências e uma população de 991 habitantes, sendo que o centro urbano, foco do presente trabalho, apresenta-se com 156 residências e 624 habitante (Figura 02).

\section{Ver Figura 02.}

Demanda de água (V, em litros por dia)

= número habitantes $\times 200 \mathrm{~L} /$ dia $(01)$

Portanto serão necessários 124800 litros de água por dia para abastecer a população, suprindo todas as necessidades.

Afirma Róbson, profissional e engenheiro da CEDAE, que o próprio sistema de distribuição, bem como o processo de tratamento, requer uma demanda significativa de água. Para um sistema pequeno, tal como do presente projeto, há necessidade de aproximadamente vinte mil litros de água por dia (20000 L/dia), para realização de limpeza de filtro, chicanas, decantador, reservatório, prédio, descarga de ponta de rede, etc.

Se juntarmos a quantidade de água necessária à comunidade com a água necessária ao sistema de abastecimento, teremos $\mathrm{V}=144800$ $\mathrm{L} /$ dia, o qual pode ser aproximado sem prejuízo para V=144000 L/dia. Se o sistema de bombeamento permanecer em funcionamento por um período $(\mathrm{T})$ de oito horas por dia $(08 \mathrm{~h} /$ dia) pode concluir que a vazão será: 


$$
Q=\frac{V}{T}
$$

Onde: $\mathrm{Q}=18000 \mathrm{~L} /$ hora, ou $5 \mathrm{~L} / \mathrm{s}$, ou $0,005 \mathrm{~m}^{3} / \mathrm{s}$ ou ainda $\mathbf{1 8} \mathbf{~ m}^{\mathbf{3}} /$ hora.

\section{b. Cálculo dos diâmetros de recalque e de sucção.}

Fórmula da ABNT (NBR-5626). Recomendada para funcionamento intermitente ou não contínuo:

$$
D r=1,3 \cdot \sqrt[4]{\frac{T}{24}} \cdot \sqrt{Q}
$$

Onde: $\mathrm{Dr}=$ diâmetro de recalque $-\mathrm{em}$ metros ou milímetros ( $\mathrm{m}$ ou $\mathrm{mm}$ ); $T$ = período - número horas de funcionamento da bomba por dia e $\mathrm{Q}$ = vazão - em metros cúbicos por segundo ou metros cúbicos por hora $\left(\mathrm{m}^{3} / \mathrm{s}\right.$ ou $\mathrm{m}^{3} / \mathrm{h}$ ).

O Ds = diâmetro de sucção é o diâmetro comercial imediatamente superior ao diâmetro de recalque calculado pela fórmula anterior em metros ou milímetros (m ou mm).

Observação: caso o valor encontrado pela fórmula da ABNT não coincida com um diâmetro comercial, o diâmetro de recalque (Dr) deverá ser um diâmetro comercial inferior ou superior ao calculado. Portanto, devemos submetê-lo ao cálculo da velocidade econômica para comprovação, em que a velocidade econômica (v) fica entre 0,5 e 4,0 metros por segundo $(\mathrm{m} / \mathrm{s})$.

$$
\mathrm{v}=\frac{4 \times Q}{\pi \times D_{r}^{2}}
$$

O Diâmetro de recalque para uma vazão de $5 \times 10^{-3} \mathrm{~m}^{3} / \mathrm{s}$ e um período de oito (8) horas por dia, será de $\mathbf{D r}=\mathbf{6 0} \mathbf{~ m m}$ e $\mathbf{D s}=\mathbf{7 5} \mathbf{~ m m}$.

$$
\begin{aligned}
& \operatorname{Dr}=1,3 \cdot \sqrt[4]{\frac{T}{24}} \cdot \sqrt{Q}=1,3 \cdot \sqrt[4]{\frac{8}{24}} \cdot \sqrt{5 \times 10^{-3}}=0,0698 m . \mathrm{Dr}=60 \mathrm{~mm} \\
& \mathrm{~V}=\frac{4 \times Q}{\pi \times D_{r}^{2}}=\frac{4 \times 0,005}{\pi \times 0,060^{2}} \approx 1,8 \mathrm{~m} / \mathrm{s} \cdot(0,5 \leq 1,8 \leq 4,0) \mathrm{m} / \mathrm{s} .
\end{aligned}
$$

\section{c. Determinação da altura manomé- trica da instalação}

O levantamento topográfico do perfil do terreno permite determinar: a altitude do local da captação; o desnível geométrico da instalação $(\mathrm{Hg})$; o comprimento real das tubulações de sucção (Ts) e de recalque (Tr) e o número de peças especiais nas tubulações, respectivamente. Com os comprimentos das tubulações e o número de peças especiais, a perda de carga é facilmente calculada pelo conhecimento dos diâmetros de sucção e de recalque.

Ver Figura 03

Altura manométrica total (Hman) corresponde ao desnível geométrico $(\mathrm{Hg})$, verificado entre os níveis da água na tomada e na chegada, acrescido de todas as perdas de carga por atrito que ocorrem nas peças especiais (perda de carga localizada) e tubulações (perda de carga distribuída), quando se bombeia um caudal (Q).

A perda de carga localizada pode ser calculada através do método dos comprimentos equivalentes, das respectivas peças especiais (Tabela 01)

Ver Tabela 01

Esses comprimentos equivalentes deverão ser adicionados ao comprimento real da tubulação para realizar o calculo da perda de carga distribuída, provocada pelo atrito entre o fluido e a rugosidade das tubulações (Tabela 02).

Ver Tabela 02

Essas perdas de carga podem ser desdobradas em perdas na sucção e perdas no recalque. Em consequência, a altura manométrica total pode ser desdobrada em duas parcelas, a saber:

- $\quad$ Altura manométrica no recalque (Hman.rec);

$$
\operatorname{Re}_{r}=\frac{4 Q}{\pi D_{r} v}
$$

Onde: $\operatorname{Re}_{r}=$ número de Reynolds no recalque, adimensional e $v=$ viscosidade da água em uma dada temperatura. 
$f_{r}=0,0055\left[1+\left(20000 \frac{\varepsilon}{D_{r}}+\frac{10^{6}}{\mathrm{Re}_{r}}\right)^{1 / 3}\right]$

Onde: $f_{r}=$ fator de atrito no recalque, adimensional; $\varepsilon=$ rugosidade absoluta - em milímetros (mm).

$$
\mathrm{Jr}=8 f_{r} \frac{Q^{2}}{\pi^{2} g D_{r}{ }^{5}}
$$

Onde: $\mathrm{Jr}=$ perda de carga unitária no recalque - em metros por metro $(\mathrm{m} / \mathrm{m})$ e $\mathrm{g}=$ aceleração da gravidade $=9,81 \mathrm{~m} / \mathrm{s}^{2}$ (metros por segundo ao quadrado).

$$
\operatorname{Ltr}=\operatorname{Tr}+\operatorname{Lr}
$$

Onde: $\operatorname{Ltr}=$ comprimento total da tubulação de recalque - em metros $(\mathrm{m}) ; \mathrm{Tr}=$ comprimento real da tubulação de recalque - em metros $(\mathrm{m})$; $\mathrm{Lr}=$ comprimento equivalente nas conexões da tubulação de recalque - em metros (m).

$$
\mathrm{Vr}=\frac{4 \times Q}{\pi \times D_{r}^{2}}
$$

Onde: $\mathrm{Vr}=$ velocidade média no recalque - em metros por segundo $(\mathrm{m} / \mathrm{s})$.

Hman.rec $=H g_{r}+J_{r} \times L t_{r}+\frac{V_{r}^{2}}{2 \times g}=H g_{r}+J_{r} \times L t_{r}+\frac{8 \times Q^{2}}{\pi^{2} \times D_{r}^{4} \times g}$

Onde: Hman.rec $=$ Altura manométrica de recalque - em metros $(\mathrm{m})$; Hgr = altura geométrica de recalque (desnível topográfico do eixo da bomba ao reservatório superior) - em metros (m).

$$
\begin{aligned}
& \operatorname{Re}_{r}=\frac{4 * 0,005}{\pi * 0,060 * 1,007 \times 10^{-6}} \Rightarrow \operatorname{Re}_{\mathbf{r}} \cong 1,05 \times 10^{5} \\
& f_{r}=0,0055\left[1+\left(20000 * \frac{1 \times 10^{-5}}{60 \times 10^{-3}}+\frac{10^{6}}{1,05 * 10^{5}}\right)^{1 / 3}\right] \Rightarrow f_{r} \cong 0,0184 \\
& I_{r}=8 * 0,0184 * \frac{0,005^{2}}{\pi^{2} * 9,81 * 0,060^{5}} \Rightarrow I_{r} \cong 0,04881 \mathrm{~m} / \mathbf{m} .
\end{aligned}
$$

\begin{tabular}{|c|c|c|c|c|}
\hline \multicolumn{3}{|c|}{ Diâmetro da tubulação de recalque: } & \multicolumn{2}{|c|}{$\mathrm{D}_{\mathrm{r}}=60,00(\mathrm{~mm})$ ou $0,06(\mathrm{~m})$} \\
\hline \multicolumn{3}{|c|}{ Comprimento real da tubulação de recalque: } & \multicolumn{2}{|c|}{$\mathrm{T}_{\mathrm{r}}=580,00(\mathrm{~m})$} \\
\hline Item & Elemento (acessórios) & Quantidade & $\begin{array}{c}\text { Comprimento } \\
\text { Equivalente } \\
\text { Unitário } \\
\end{array}$ & $\begin{array}{c}\text { Comprimento } \\
\text { Equivalente } \\
\text { Total } \\
\end{array}$ \\
\hline 01 & Joelho de $90^{\circ}$ & 01 & 3,40 & 3,40 \\
\hline 02 & Curva de $90^{\circ}$ & 08 & 1,30 & 10,40 \\
\hline 03 & Curva de $45^{\circ}$ & 03 & 0,70 & 2,10 \\
\hline 04 & Tê de passagem direta & 01 & 2,30 & 2,30 \\
\hline 05 & Tê de passagem lateral & 01 & 7,60 & 7,60 \\
\hline 06 & Registro de gaveta & 01 & 0,80 & 0,80 \\
\hline 07 & Saída de canalização & 01 & 3,30 & 3,30 \\
\hline 08 & Válvula de retenção horizontal & 01 & 7,10 & 7,10 \\
\hline 09 & Ampliação concêntrica & 01 & -- & -- \\
\hline & & & Total $=$ & $37,00 \mathrm{~m}$ \\
\hline & $\mathbf{L t}_{\mathrm{r}}=\mathbf{T}_{\mathrm{r}}+\mathbf{L}_{\mathrm{r}}=$ & $30,00+37,00$ & $617,00 \mathrm{~m}$ & \\
\hline
\end{tabular}

A Tabela 03, abaixo, apresenta uma síntese dos dados, cálculos e resultados obtidos para determinação do comprimento virtual total na tubulação de recalque.

Tabela 03: Cálculo do comprimento total da tubulação de recalque

$$
\text { Hman.rec }=46,40+(0,04881 \times 617)+\frac{8 \times 0,005^{2}}{\pi^{2} \times 0,06^{4} \times \mathbf{9 , 8 1}} \Rightarrow \text { Hman.rec }=76,67 \mathbf{m}
$$

- $\quad$ Altura manométrica na sucção (Hman.rec); 


$$
\operatorname{Re}_{s}=\frac{4 Q}{\pi D_{s} v}
$$

Onde: $\mathrm{Re}_{s}=$ número de Reynolds na sucção, adimensional;

$$
f_{s}=0,0055\left[1+\left(20000 \frac{\varepsilon}{D_{s}}+\frac{10^{6}}{\operatorname{Re}_{s}}\right)^{1 / 3}\right]
$$

Onde: $f_{s}=$ fator de atrito na sucção, adimensional.

$$
\mathrm{Js}=8 f_{s} \frac{Q^{2}}{\pi^{2} g D_{s}^{5}}
$$

Onde: Js = perda de carga unitária na sucção em metros por metro $(\mathrm{m} / \mathrm{m})$

$$
\mathrm{Lts}=\mathrm{Ts}+\mathrm{Ls}
$$

Onde: Lts $=$ comprimento total da tubulação de sucção - em metros (m); Ts = comprimento real da tubulação de sucção - em metros (m); Ls = comprimento equivalente das conexões na tubulação de sucção - em metros (m). Obs.: Vs = velocidade média na sucção pode ser considerada desprezível.

Hman.suc $=H g_{s}+J_{s} \times L t_{s}+\frac{V_{s}^{2}}{2 \times g}=H g_{s}+J_{s} \times L t_{s}$

Onde: Hman.suc $=$ Altura manométrica de sucção - em metros (m); Hgs = altura geométrica de sucção (desnível topográfico do reservatório da captação ao eixo da bomba) - em metros (m).

$\operatorname{Re}_{\mathbf{s}}=\frac{4.5 \times 10^{-3}}{\pi .75 \times 10^{-3} \cdot 1,007 \times 10^{-6}} \Rightarrow \operatorname{Re}_{\mathbf{s}} \cong 8,4 \times 10^{4}$ $f_{s}=0,0055\left[1+\left(20000 * \frac{1 \times 10^{-5}}{75 \times 10^{-3}}+\frac{10^{6}}{8,4 \times 10^{4}}\right)^{1 / 3}\right]$

A Tabela 04, abaixo, apresenta uma síntese dos dados, cálculos e resultados obtidos

\begin{tabular}{|c|c|c|c|c|}
\hline \multicolumn{3}{|c|}{ Diâmetro da tubulação de sucção: } & \multicolumn{2}{|c|}{$\mathrm{D}_{\mathrm{s}}=75,00(\mathrm{~mm})$ ou $0,075(\mathrm{~m})$} \\
\hline \multicolumn{3}{|c|}{ Comprimento real da tubulação de sucção: } & \multicolumn{2}{|c|}{$\mathrm{T}_{\mathrm{s}}=6,00(\mathrm{~m})$} \\
\hline Item & Elemento (acessórios) & Quantidade & $\begin{array}{c}\text { Comprimento } \\
\text { Equivalente } \\
\text { Unitário }\end{array}$ & $\begin{array}{c}\text { Comprimento } \\
\text { Equivalente } \\
\text { Total }\end{array}$ \\
\hline 01 & Válvula de pé com crivo & 01 & 25,00 & 25,00 \\
\hline 02 & Curva $90^{\circ}$ & 01 & 1,40 & 1,40 \\
\hline 03 & Registro de gaveta & 01 & 0,90 & 0,9 \\
\hline 04 & Tê com passagem direta & 01 & 2,40 & 2,4 \\
\hline 05 & Redução excêntrica & 01 & -- & -- \\
\hline \multicolumn{4}{|c|}{ Total $=$} & $29,70 \mathrm{~m}$ \\
\hline \multicolumn{5}{|c|}{$\mathrm{Lt}_{\mathrm{s}}=\mathrm{T}_{\mathrm{s}}+\mathrm{L}_{\mathrm{s}}=6,00+29,70=35,70 \mathrm{~m}$} \\
\hline
\end{tabular}
para determinação do comprimento virtual total na tubulação de sucção.

Tabela 04: Cálculo do comprimento total da tubulação de sucção

Hman.suc $=3,60+(0,01645 \times 35,7) \Rightarrow$ Hman.suc $=4,19 \mathrm{~m}$

Concluímos, portanto que altura manométrica é a soma das duas parcelas:

Hman $=$ Hman.rec + Hman.suc

$\operatorname{Hman}=76,67+4,19 \Rightarrow$ Hman $\cong \mathbf{8 0} \mathbf{~}$. 


\section{d. Potência necessária ao funciona- mento da bomba (Pot).}

Pot $=\gamma \cdot Q . H m a n$ (watts) ou, Pot :

- A potência absorvida pela bomba é calculada por:

$$
\eta_{M}=\frac{\operatorname{Pot}_{B}}{\operatorname{Pot}_{M}} \therefore \operatorname{Pot}_{M}=\frac{\text { Pot }_{B}}{\eta_{M}}
$$

- A potência do motor é calculada por:

$$
\eta_{M}=\frac{\text { Pot }_{B}}{\text { Pot }_{M}} \therefore \text { Pot }_{M}=\frac{\text { Pot }_{B}}{\eta_{M}}
$$

O motor que aciona a bomba deverá trabalhar sempre com uma folga ou margem de segurança a qual evitará que o mesmo venha, por uma razão qualquer, operar com sobrecarga. Portanto, recomenda-se que a potência ne- cessária ao funcionamento da bomba (Pot) seja acrescida de uma folga, conforme especificação a seguir (para motores elétricos): Até $02 \mathrm{cv}$ $50 \%$; de 02 a 05 cv - 30\%; de 05 a 10 cv - 20\%; de 10 a $20 \mathrm{cv}-15 \%$ e acima de $20 \mathrm{cv}-10 \%$. Para motores a óleo diesel, recomenda-se uma margem de segurança de $25 \%$ e, a gasolina de $50 \%$, independente da potência calculada.

- Assim a potência instalada $\left(\right.$ Pot $\left._{\text {nominal }}\right)$ fica:

$$
\text { Pot }_{\text {nomin } a l}=\operatorname{Pot}_{M}+\text { folga }(\%)
$$

Para a determinação da potência instalada $\left(\right.$ Pot $\left._{\text {nominal }}\right)$, deve-se observar que os motores elétricos nacionais são fabricados com as seguintes potências comerciais, em cv (Motores Kohlbach $-1200 \mathrm{rpm}-60 \mathrm{~Hz}): 1 / 4-1 / 3-1 / 2$ $-3 / 4-1-1 \frac{1}{2}-2-3-4-5-7 \frac{1}{2}-10-12$ $1 / 2-15-20-25-30-40-50-60-75-$ $100-125$.

Portanto teremos:

Pot $=9800 * 0.005 * 80=3920 \mathrm{~W}$ ou $P o t \cong 3,9 \mathrm{KW}$.

Potência absorvida pela bomba: $\operatorname{Pot}_{B}=\frac{\text { Pot }}{\eta_{B}} \therefore \operatorname{Pot}_{B}=\frac{3,9}{52 \%}=\frac{3,9}{0,52}=7,5 \mathrm{KW}$

Potência do motor: $\operatorname{Pot}_{M}=\frac{\operatorname{Pot}_{B}}{\eta_{M}} \therefore \operatorname{Pot}_{M}=\frac{7,5}{82 \%}=\frac{7,5}{0,82}=9,15 \mathrm{KW}$

Motores com potência entre $5-10 \mathrm{cv}$, admitir uma folga de $20 \%$.

Assim a potência instalada fica: $P o t_{n o \text { min } a l}=P o t_{M}+20 \%=10,98 \cong 11 \mathbf{K W}$ ou $15 \mathbf{c v}$.

\section{e. Cavitação / Npsh}

Cavitação é um fenômeno semelhante à ebulição, que pode ocorrer com água em regiões de baixa pressão do sistema de recalque durante um processo de bombeamento, ou seja, na canalização de sucção e é identificado por ruídos e vibrações. Essas bolhas de vapor de água implodem quando chega a regiões de maior pressão, havendo liberação de energia que por sua vez é absorvida pelo rotor ou palhetas da bomba, como esse pro- cesso é contínuo e sempre no mesmo local acaba provocando estragos por perda de resistência mecânica nos mesmos. Para evitar tal fenômeno, deve-se analisar o NPSH (Net Positive Succion Head) disponível e requerido. O NPSH disponível refere-se à "carga energética líquida e disponível na instalação" para permitir a sucção do fluido, ou seja, diz respeito às grandezas físicas associadas à instalação e ao fluido. Esse NPSH deve ser estudado pelo projetista da instalação, através da seguinte expressão: 
NPSH disponível = energia disponível na instalação para sucção - em metros (m); Hatm $=$ pressão atmosférica local - em metros $(\mathrm{m})$;

Ver Tabela 05

Hs = altura de sucção; é negativa quando a bomba está afogada, e positiva quando estiver acima do nível d'água - em metros (m);

$\mathrm{Hv}=$ pressão de vapor do fluido em função da sua temperatura - em metros (m);

\section{Ver Tabela 06}

$\Delta \mathrm{Hs}=$ perda de carga total na linha de sucção - em metros (m);

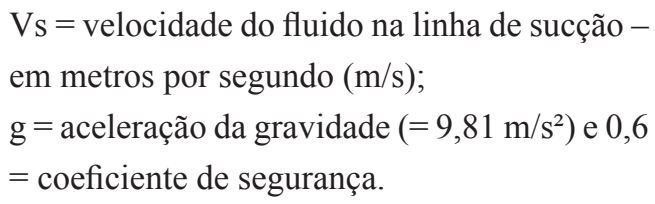

O NPSH requerido é a "carga energética líquida requerida pela bomba" para promover a sucção. Esse NPSH é objeto de estudo do fabricante, sendo fornecido graficamente através de catálogos.

\section{Portanto temos:}

$$
\text { NPSH disponível }=9,70-\left[3,6+0,33+0,59+\left(1,13^{2} / 2 * 9,81\right)+0,6\right.
$$

\section{NPSH disponível $=4,51 \mathrm{~m}$.}

Observa-se, portanto, que a energia disponível na instalação para sucção deve ser maior que a energia requerida pela bomba, logo NPSH disponível $\geq$ NPSH requerido. Caso contrário, haverá cavitação em decorrência de uma sucção deficiente.

\section{Resultados}

Conforme os parâmetros vazão $(\mathrm{Q}=18$ $\left.\mathrm{m}^{3}\right)$, altura manométrica $(\mathrm{Hm}=80 \mathrm{~m})$ e NPSH disponível $(4,51 \mathrm{~m}) \geq \mathrm{NPSH}$ requerido, cinco (05) bombas supostamente podem ser utilizadas:

BOMBA - 1: apresenta boa potência de $15 \mathrm{cv}$ e rendimento baixo de $49 \%$, de acordo com Figura 04

Figura 04.

BOMBA - 2: apresenta baixa potência de $11,85 \mathrm{cv}$ e baixo rendimento de $45 \%$, de acordo com Figura 05.
BOMBA - 3: apresenta baixa potência de $12,70 \mathrm{cv}$ e baixo rendimento de $42 \%$, de acordo com Figura 06.

Figura 06.

BOMBA - 4: apresenta boa potência de 20cv e rendimento regular de 61\%, de acordo com Figura 07.

Figura 07.

BOMBA - 5: apresenta boa potência de $16,67 \mathrm{cv}$ e rendimento baixo de $32 \%$, de acordo com Figura 08.

Figura 08 .

\section{Considerações Finais}

A opção que se mostrou mais adequada às condições de operação foi a Bomba - 4 (Figura 07), apesar de trabalhar próximo de seu limite máximo para altura manométrica. Tal fato pode levar à sua substituição em longo prazo devido ao envelhecimento da tubulação. Na prática, o processo de determinação

Figura 05. 
de moto bomba para um sistema de recalque é bem mais complexo do que parece, pois as bombas comumente encontradas no mercado são especificas para uma determinada condição de trabalho. Portanto, não bastam ter em mãos um mosaico, diagrama ou tabela de sele-

\section{Referências Bibliográficas}

1. PORTO, R.M. "Hidráulica Básica". EESC-USP, São Carlos, SP, $3^{\text {a }}$ edição, 2004.

2. CARESTIATO, A. \& ABREU, C.S. "PROGRAMA CURSO D'ÁGUA". CEIVAP

3. Comitê de integração da Bacia do Rio Paraíba do Sul, RIO de JANEIRO, 1999.

4. PAUlA, D.A. "HISTÓRIA de RIO CLARO”. ELETRONUCLEAR, RIO de JANEIRO, 2004. ção de bombas, todos os parâmetros inerentes devem ser levados em consideração para definir a opção mais viável, se isso não for obtido, todo o sistema (vazão, rede de sucção e de recalque) deve ser redimensionado.

5. JOSÉ ALFEU ALMEIDA DE SÁ MARQUES E JOAQUIM JOSÉ DE OLIVEIRA SOUSA. "Hidráulica Urbana - Sistemas de Abastecimento de Água e de Drenagem de Águas Residuais”. Porto, 2a Edição, 2011.

6. MACINTYRE, A. J. "Bombas e Instalações de Bombeamento". Guanabara S.A. Rio de Janeiro, RJ, $2^{\mathrm{a}}$ edição, 1997.

7. AZEVEDO NETTO, J.M. \& ALVAREZ, G.A. "Manual de Hidráulica". Editor Edgard Blucher, São Paulo, $8^{a}$ edição, 2000 .
Endereço para Correspondência:

Élcio Nogueira

elcionogueira@hotmail.com

Centro Universitário de Volta Redonda - UniFOA

Campus Olezio Galotti

Av. Paulo Erlei Alves Abrantes, $n^{\circ} 1325$

Três Poços - Volta Redonda - RJ

CEP: 27240-000 


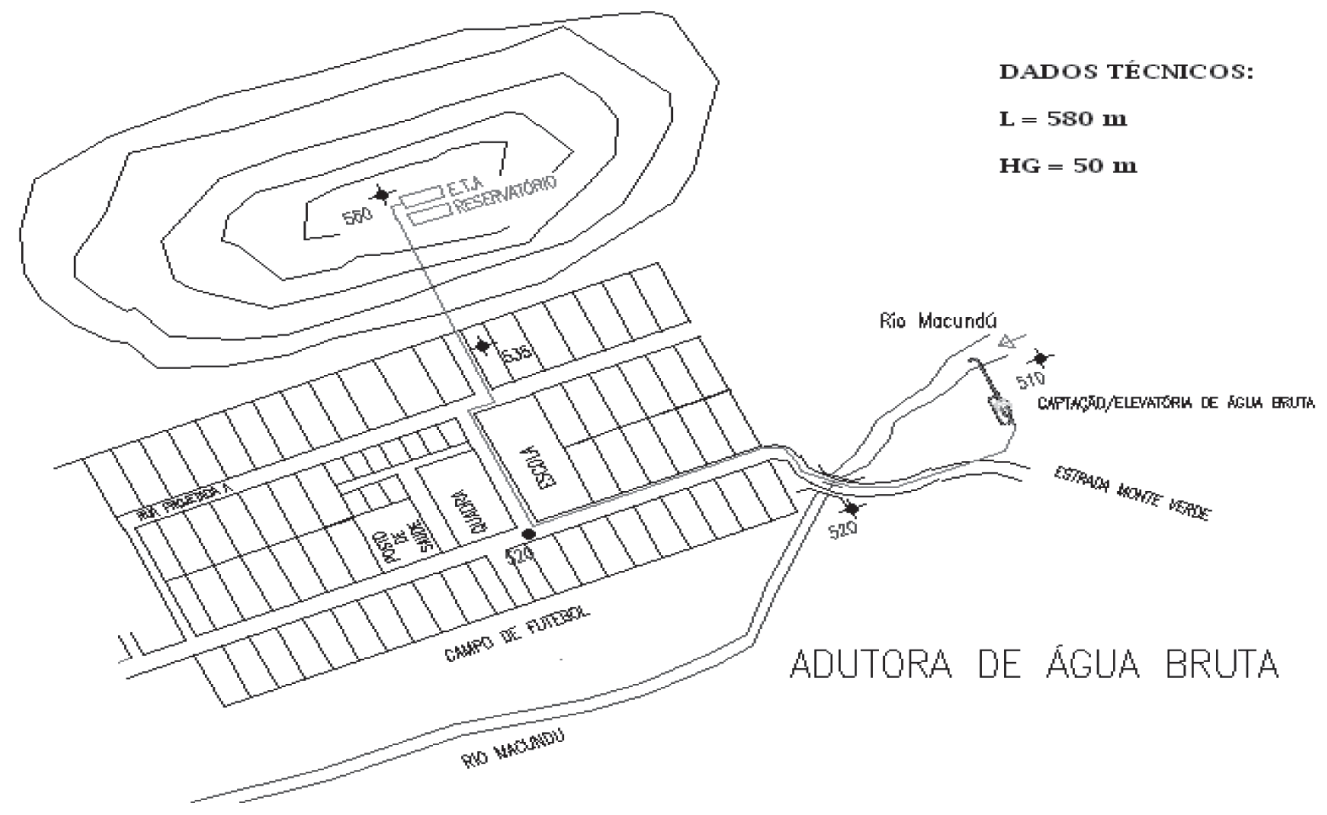

Figura 01: Esboço do levantamento topográfico da comunidade de MACUNDÚ

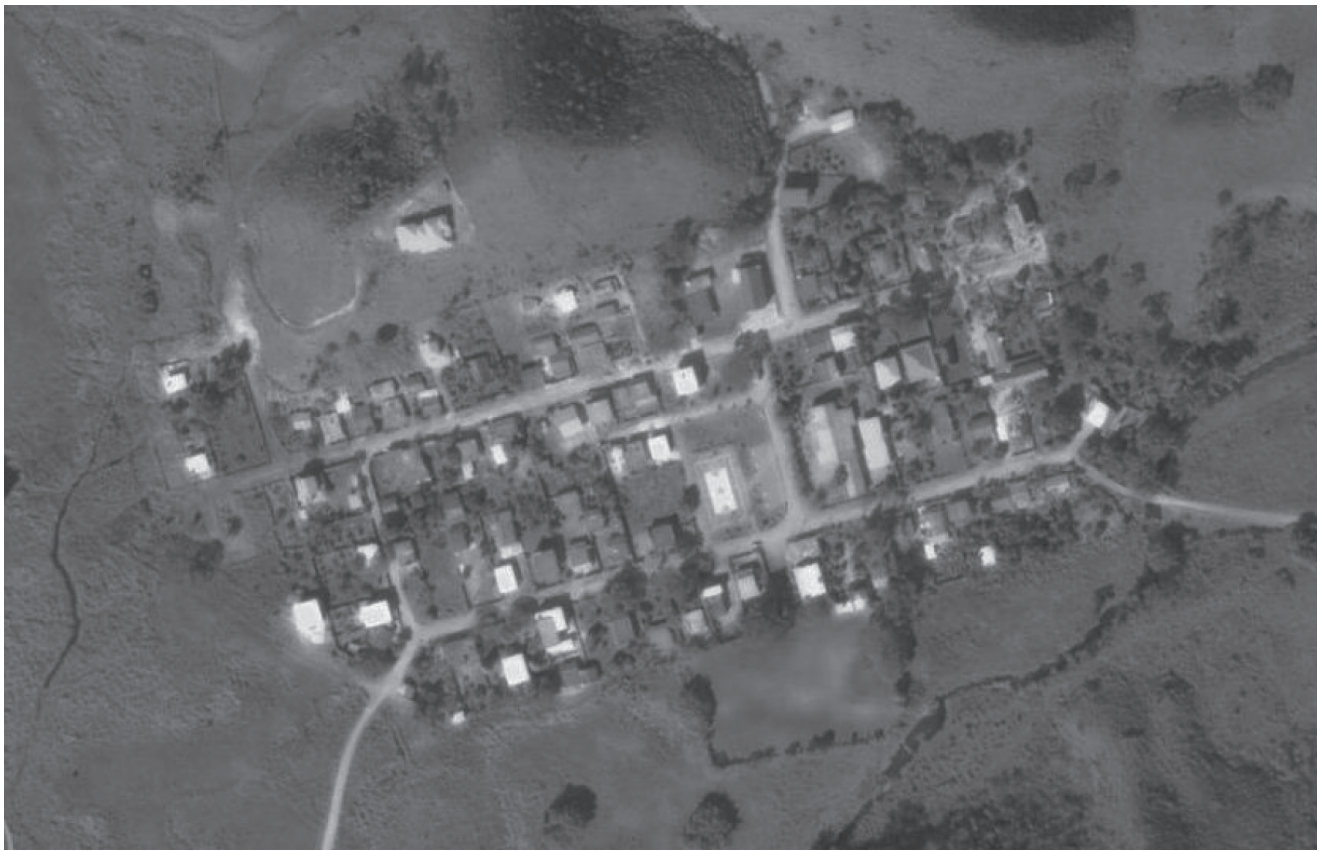

Figura 02: Vista aérea da comunidade do Macundú, Rio Claro, RJ 


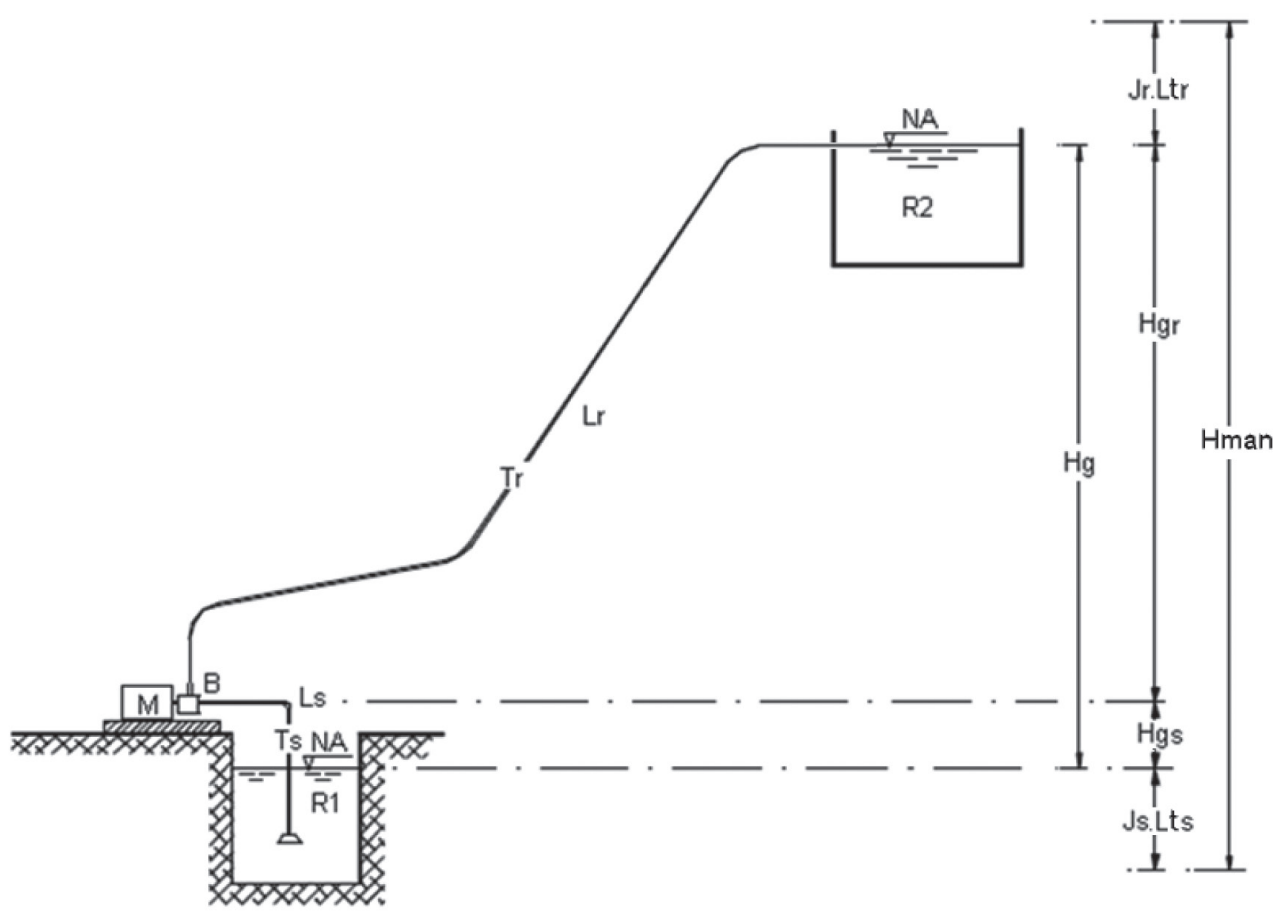

Figura 03: Esquema simplificado de um sistema de recalque.

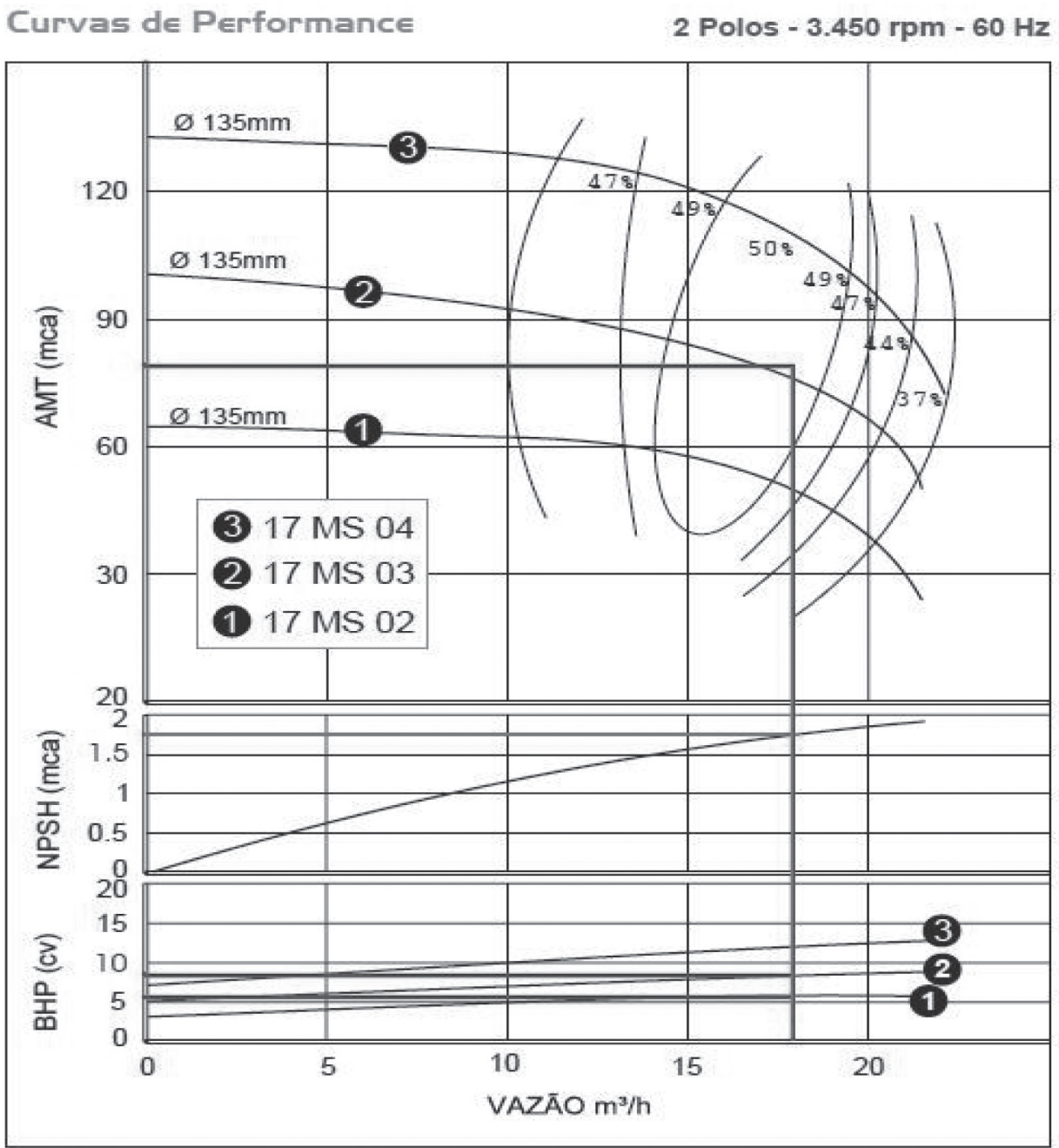

Figura 04: BOMBA - 1 


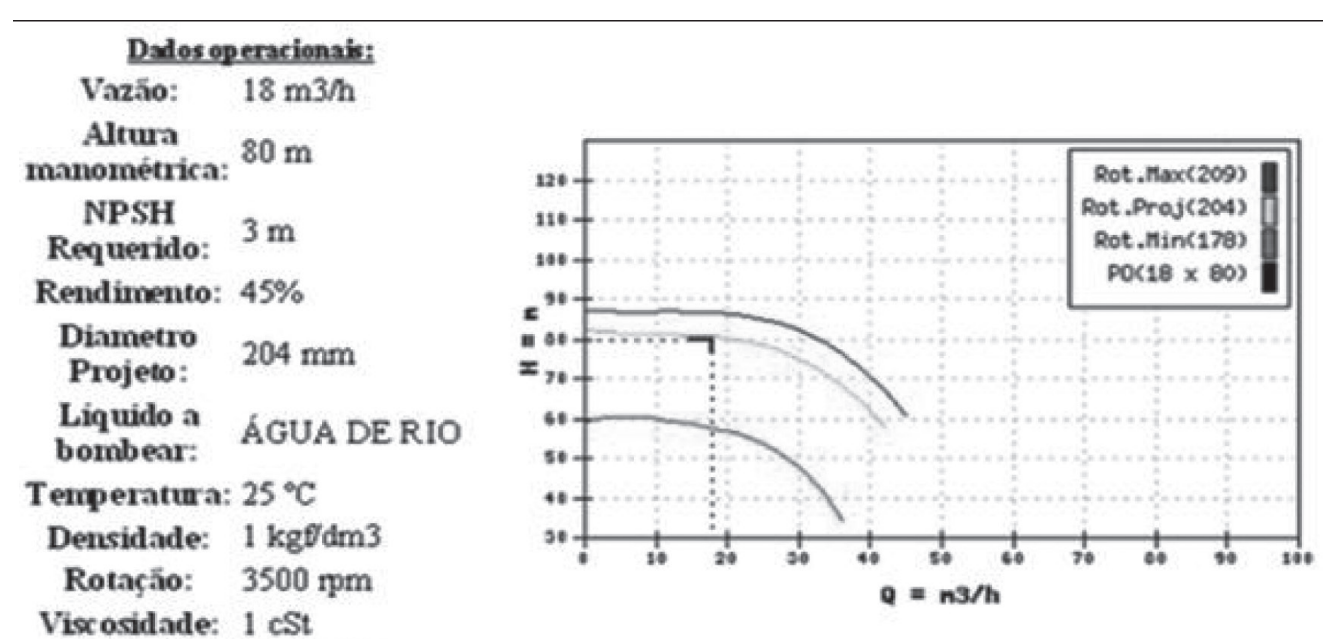

Viscosidade: $1 \mathrm{cSt}$

Potencia: $11.85 \mathrm{CV}$

Figura 05: BOMBA - 2

Dalos operacionais:

Vazăo: $18 \mathrm{~m} 3 / \mathrm{h}$

Altura $80 \mathrm{~m}$

manométrica: $80 \mathrm{~m}$

NPSH
Requerido: $2.4 \mathrm{~m}$

Rendimento: $42 \%$

Diametro $199 \mathrm{~mm}$

Projeto:

Liquido a ÁGUA DERIO
bombear:

Temperatura: $25^{\circ} \mathrm{C}$

Densidade: $1 \mathrm{~kg} f \mathrm{dm} 3$

Rotaçăo: $\quad 3500 \mathrm{~mm}$

Vixcosidade: $1 \mathrm{cSt}$

Potencia: $12.7 \mathrm{CV}$

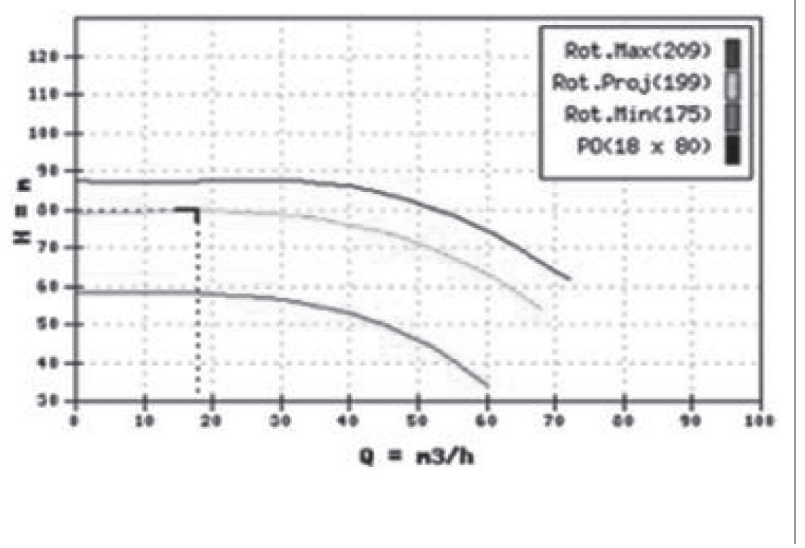

Figura 06: BOMBA - 3 


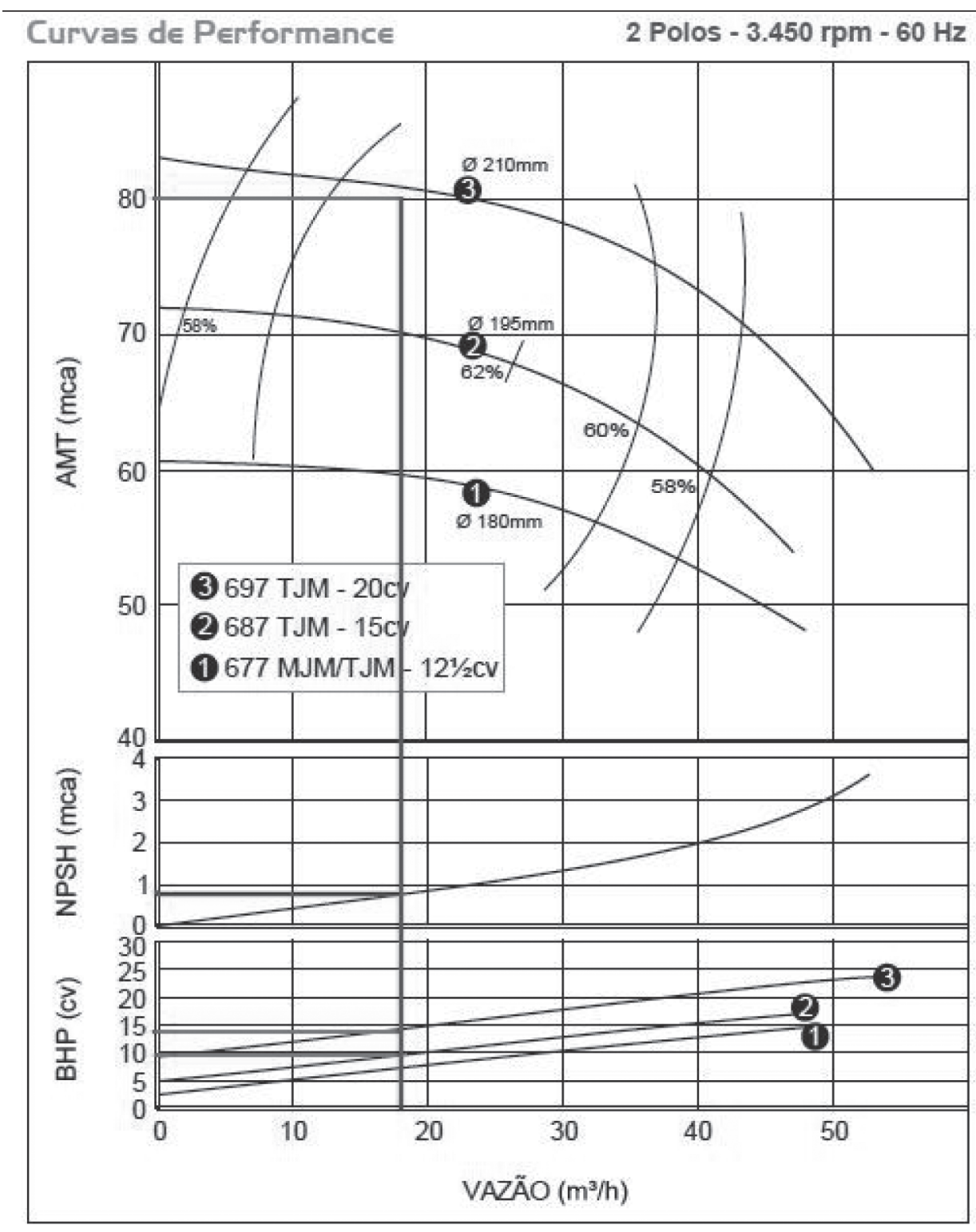

Figura 07: BOMBA - 4

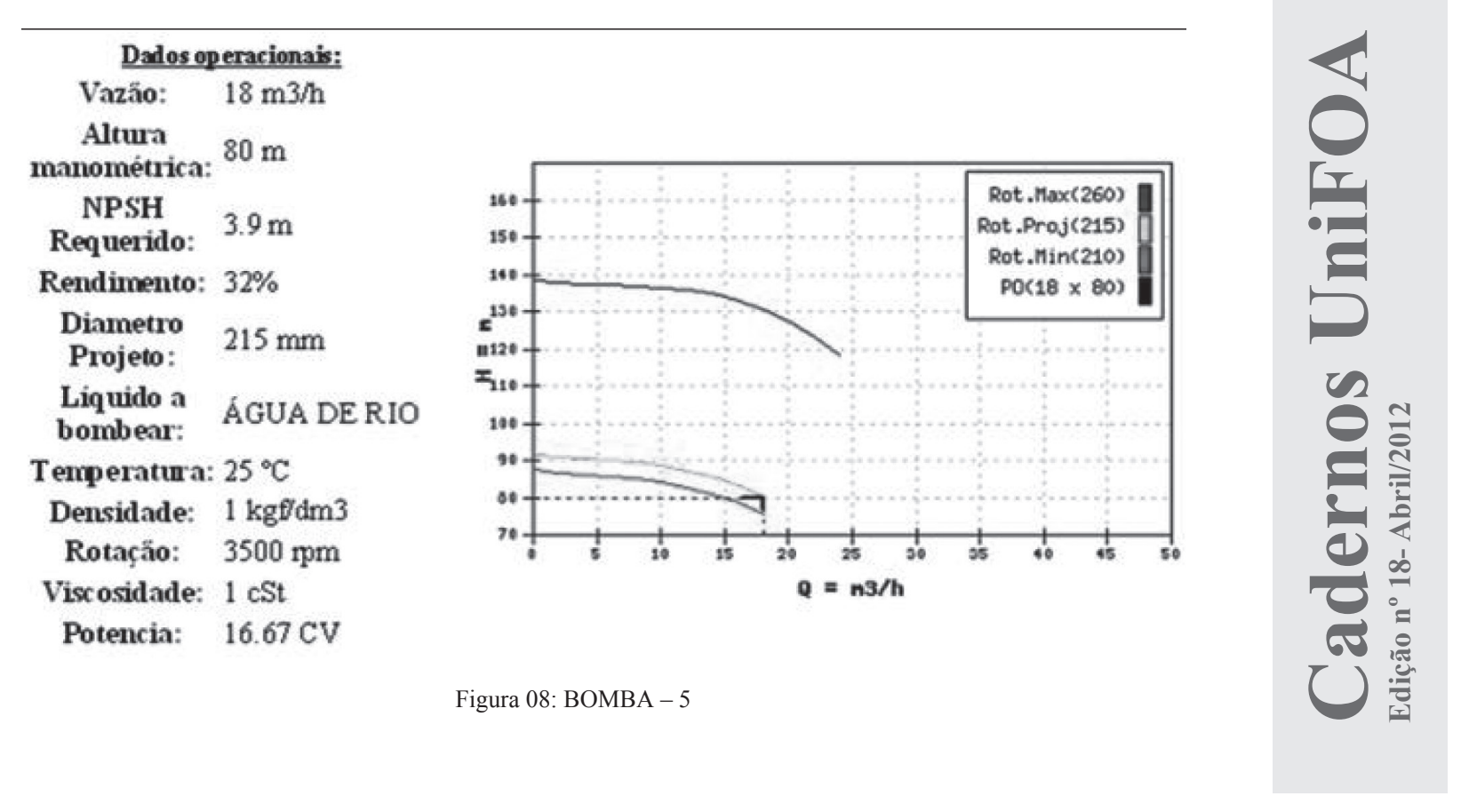


9. Lista De Tabelas

Tabela 01: Comprimento equivalente em metros das principais peças especiais.

\begin{tabular}{|c|c|c|c|c|c|c|c|c|c|c|}
\hline \multirow{2}{*}{ Tipo de Peça } & \multicolumn{10}{|c|}{ Diâmetros comerciais (mm) } \\
\cline { 2 - 12 } & $\mathbf{5 0}$ & $\mathbf{6 3}$ & $\mathbf{7 5}$ & $\mathbf{1 0 0}$ & $\mathbf{1 2 5}$ & $\mathbf{1 5 0}$ & $\mathbf{2 0 0}$ & $\mathbf{2 5 0}$ & $\mathbf{3 0 0}$ & $\mathbf{3 5 0}$ \\
\hline Curva 90 & 0,6 & 0,8 & 1,0 & 1,3 & 1,6 & 1,9 & 2,4 & 3,0 & 3,6 & 4,4 \\
\hline Curva 45 & 0,4 & 0,5 & 0,6 & 0,7 & 0,9 & 1,1 & 1,5 & 1,8 & 2,2 & 2,5 \\
\hline Entr. normal & 0,7 & 0,9 & 1,1 & 1,6 & 2,0 & 2,5 & 3,5 & 4,5 & 5,5 & 6,2 \\
\hline Entr. borda & 1,5 & 1,9 & 2,2 & 3,2 & 4,0 & 5,0 & 6,0 & 7,5 & 9,0 & 11,0 \\
\hline Reg. gav. ab. & 0,4 & 0,4 & 0,5 & 0,7 & 0,9 & 1,1 & 1,4 & 1,7 & 2,1 & 2,4 \\
\hline Reg. gl. ab & 17,0 & 21,0 & 26,0 & 34,0 & 43,0 & 51,0 & 67,0 & 85,0 & 102 & 120 \\
\hline Tê pass. direita & 1,1 & 1,3 & 1,6 & 2,1 & 2,7 & 3,4 & 4,3 & 5,5 & 6,1 & 7,3 \\
\hline Tê saída de lado & 3,5 & 4,3 & 5,2 & 6,7 & 8,4 & 10,0 & 13,0 & 16,0 & 19,0 & 22,0 \\
\hline Tê saída bilater & 3,5 & 4,3 & 5,2 & 6,7 & 8,4 & 10,0 & 13,0 & 16,0 & 19,0 & 22,0 \\
\hline Válv. pé/cr. & 14,0 & 17,0 & 20,0 & 23,0 & 30,0 & 39,0 & 52,0 & 65,0 & 78,0 & 90,0 \\
\hline Saída de canal & 1,5 & 1,9 & 2,2 & 3,2 & 4,0 & 5,0 & 6,0 & 7,5 & 9,0 & 11,0 \\
\hline Válvula retenção & 4,2 & 5,2 & 6,3 & 8,4 & 10,0 & 13,0 & 16,0 & 20,0 & 24,0 & 28,0 \\
\hline
\end{tabular}

Tabela 04: Valores de rugosidade absoluta $(\varepsilon)$ dos materiais empregados em condutos.

\begin{tabular}{|l|l|}
\hline Tipo de material & $($ a) $-(\mathbf{m m})$ \\
\hline Ferro fundido novo & $0,26-1$ \\
\hline Ferro fundido enferrujado & $1-1,5$ \\
\hline Ferro fundido incrustado & $1,5-3$ \\
\hline Ferro fundido asfaltado & $0,12-0,26$ \\
\hline Aço laminado novo & 0,0015 \\
\hline Aço comercial & 0,046 \\
\hline Aço rebitado & $0,092-9,2$ \\
\hline Aço asfaltado & 0,04 \\
\hline Aço galvanizado & 0,15 \\
\hline Aço soldado liso & 0,1 \\
\hline Aço muito corroído & 2,0 \\
\hline Aço rebitado, com cabeças cortadas. & 0,3 \\
\hline Cobre ou vidro & 0,0015 \\
\hline Concreto centrifugado & 0,07 \\
\hline Cimento alisado & $0,3-0,8$ \\
\hline Cimento bruto & $1-3$ \\
\hline Madeira aplainada & $0,2-0,9$ \\
\hline Madeira não aplainada & $1,0-2,5$ \\
\hline Alvenaria de pedra bruta & $8-15$ \\
\hline Tijolo & 05 \\
\hline Plástico (PVC) & $0,01-0,06$ \\
\hline Alvenaria de pedra regular & 01 \\
\hline
\end{tabular}


Tabela 05: Pressão atmosférica em função da altitude.

\begin{tabular}{|c|c|}
\hline Altitude (m) & Pressão atmosférica (m) \\
\hline 0,0 & 10,33 \\
\hline 300 & 9,96 \\
\hline 600 & 9,59 \\
\hline 900 & 9,22 \\
\hline 1200 & 8,88 \\
\hline 1500 & 8,54 \\
\hline 1800 & 8,20 \\
\hline 2100 & 7,89 \\
\hline 2400 & 7,58 \\
\hline 2700 & 7,31 \\
\hline 3000 & 7,03 \\
\hline
\end{tabular}

Tabela 06: Pressão de vapor da água em metros $(\mathrm{m})$ para diferentes temperaturas.

\begin{tabular}{|c|c|c|}
\hline Temperatura $^{\circ} \mathbf{C}$ & Peso específico $\mathbf{g}\left(\mathbf{k N} / \mathbf{m}^{\mathbf{3}}\right)$ & $\begin{array}{c}\text { Pressão de } \\
\text { Vapor (m) })\end{array}$ \\
\hline 15 & 9,798 & $\mathbf{0 , 1 7}$ \\
\hline 20 & 9,789 & $\mathbf{0 , 2 5}$ \\
\hline 25 & 9,777 & $\mathbf{0 , 3 3}$ \\
\hline 30 & 9,764 & $\mathbf{0 , 4 4}$ \\
\hline 40 & 9,730 & $\mathbf{0 , 7 6}$ \\
\hline 50 & 9,689 & $\mathbf{1 , 2 6}$ \\
\hline 60 & 9,642 & $\mathbf{2 , 0 3}$ \\
\hline 70 & 9,589 & $\mathbf{3 , 2 0}$ \\
\hline 80 & 9,530 & $\mathbf{4 , 9 6}$ \\
\hline 90 & 9,466 & $\mathbf{7 , 1 8}$ \\
\hline 100 & 9,399 & $\mathbf{1 0 , 3 3}$ \\
\hline
\end{tabular}

